\title{
Effect of selenium applied to pasture on the selenium status of grazing sheep
}

\author{
A.M. MOORHOUSE ${ }^{1}$, C.T. WESTWOOD ${ }^{1}$, A.J. DUMBLETON ${ }^{1}$, L.P. DONNELLY ${ }^{1}$ \\ and L.A. BRIDGER ${ }^{2}$ \\ ${ }^{1}$ Wrightson Research, PO Box 939, Christchurch \\ ${ }^{2}$ Kiwitech Limited, PO Box 444, Hawera
}

\begin{abstract}
Blood selenium concentrations and liveweight gains were assessed for sheep grazing pastures treated with different selenium supplements over a 2-year period. Three 0.5 hectare irrigated blocks with pasture selenium concentrations of less than $0.04 \mu \mathrm{g} / \mathrm{g}$ DM were identified near Lincoln, Canterbury during 1997. Treatments applied in early November 1997 were: (1) $1 \mathrm{~kg} / \mathrm{ha}$ of an experimental selenium product (SRSe5, containing $10 \mathrm{~g}$ selenium); (2) $1 \mathrm{~kg} / \mathrm{ha}$ of a commercially available slow release selenium product (positive control, containing $10 \mathrm{~g}$ selenium) and (3) nil selenium treatment (negative control); all treatments used $60 \mathrm{~kg}$ urea/ha as the carrier. Treatments were stocked at 30 lambs/ha in November 1997. Liveweight gains and concentrations of blood selenium were monitored fortnightly for the first 4 months of the study and monthly thereafter. Following mating in April 1998, blood selenium concentrations and liveweight gains of spring born progeny were assessed. Ewes grazing the SRSe5 and positive control treatments had significantly greater concentrations of blood selenium than the negative control group and the concentrations for the SRSe5 group were significantly greater than from the positive control. Negative control ewes and their lambs were removed from the study at lambing due to low blood selenium concentrations and concerns regarding their health. Concentrations of

Keywords: pasture, selenium, sheep, supplementation, topdressing

\section{Introduction}

First reported in New Zealand in 1958, selenium deficiency affects up to $30 \%$ of New Zealand's agricultural area (Grace 1994). While plants have no known requirement for selenium, extensive trialling has established significant, positive associations between blood concentrations of selenium and production responses by grazing animals (Wichtel 1994). Supplementation options include drenches, injectable products, slow release intra-ruminal boluses or selenised feed additives. Annual pasture applications of $10 \mathrm{~g}$ of sodium selenate per hectare have been demonstrated as a costeffective method by which animal selenium deficiencies may be prevented (Hupkens Van Der Elst \& Watkinson 1977). Pasture-applied selenium products offer a low cost, efficacious method of selenium supplementation with considerably lower labour inputs than other methods of animal treatment. This paper presents results from a 2-year study that investigated the efficacy of a new slow release pasture selenium supplement. Liveweight gains and concentrations of blood selenium in ewes grazing pasture where the new selenium product was applied were compared with the selenium status and performance of ewes grazing pastures supplemented with a commercially available slow release pasture selenium product and ewes grazing selenium deficient pastures.
\end{abstract} blood selenium did not differ significantly between lambs of SRSe5 and positive control ewes born in the second year of the study. Lamb and ewe blood selenium concentrations were highly correlated. Liveweight gains did not differ significantly between SRSe5, positive control or negative control groups for ewes or lambs during either year of the study. This study demonstrated that the application of selenium to pastures is a highly effective longterm strategy by which concentrations of blood selenium may be elevated in sheep under New Zealand pastoral conditions. While liveweights did not differ significantly between treatments during either year of the study, the small numbers of animals used limited the power with which differences could be detected between treatments.

\section{Materials and methods}

The study was conducted during a 2-year period from November 1997 to March 1999. For the purposes of this paper, we have defined 'Year 1' as data collected from ewes on treatments from November 1997 until lambing during August/September 1998. 'Year 2' refers to data from progeny born to 'Year 1' ewes during the 1998 spring lambing season.

\section{Site selection and preparation}

During early 1997, an irrigated 1.5 ha study site was identified on Templeton silt loam near Lincoln, Canterbury, New Zealand. Baseline pasture selenium concentrations were identified as less than $0.04 \mu \mathrm{g} / \mathrm{g}$ 
DM using hydride generation atomic absorption spectroscopy (R.J. Hill Laboratories Ltd, Hamilton, New Zealand). The study site was sprayed with Roundup (3 $\mathrm{L} / \mathrm{ha}$ ) and Versatil (0.7 L/ha) and sown in April 1997 with a commercial ryegrass/clover mixture (nil endophyte Grasslands Pacific ryegrass, $15 \mathrm{~kg} / \mathrm{ha}$; Maverick Gold ryegrass, $5 \mathrm{~kg} / \mathrm{ha}$; Superstrike Tahora white clover, $3 \mathrm{~kg} / \mathrm{ha}$; and Prillcote Endura Caucasian clover, $2 \mathrm{~kg} / \mathrm{ha})$. Superphosphate $(600 \mathrm{~kg} / \mathrm{ha})$ and Cropmaster $15(50 \mathrm{~kg} / \mathrm{ha})$ were applied at the time of pasture establishment.

Three non-replicated 0.5 ha plots were randomly assigned as (1) new slow release selenium product (treatment; SRSe5); (2) a commercially available slow release selenium product (positive control; PC); and (3) nil selenium treatment (negative control; NC). Selenium treatments SRSe5 and PC were each applied to study plots at a rate of $1 \mathrm{~kg} / \mathrm{ha}$, mixed with $60 \mathrm{~kg}$ urea/ha, once during November 1997. The negative control received $60 \mathrm{~kg}$ urea/ha only.

\section{Animal selection}

An even line of 50 Coopworth ewe lambs were selected from a commercial flock in April 1997. Blood samples were collected from the jugular vein using $10 \mathrm{~mL}$ vacutainers from 10 randomly selected animals to monitor baseline concentrations of blood selenium. Lambs were maintained on low selenium pastures (forage selenium $<0.04 \mu \mathrm{g} / \mathrm{g}$ DM) adjacent to the study site between April and October 1997 during which time blood selenium declined from a mean concentration of $1330 \mathrm{nmol} / \mathrm{L}$ (April 1997) to $360 \mathrm{nmol} / \mathrm{L}$ (September 1997). Fifteen animals per plot were randomly allocated to SRSe5, PC or NC plots, treated with intra-ruminal copper needles (Bomac Labs. Ltd), Permaco cobalt intraruminal bullets (Schering-Plough Animal Health Ltd) and an anthelmintic drench to control internal parasites before being placed on the study in November 1997. The study was under the supervision of the Lincoln University Animal Ethics committee.

\section{Grazing and animal management}

The experimental animals were managed identically with respect to grazing management. Pasture dry matter covers were assessed monthly using an electronic dry matter probe, lucerne hay of low selenium concentration $(<0.04$ $\mu \mathrm{g} / \mathrm{g} \mathrm{DM}$ ) was fed strategically to maintain pasture covers during periods of feed deficit.

\section{Year 1}

Study animals were set-stocked during the first 5 months of Year 1. Ewes were removed from the study plots in April 1998 to an adjacent low selenium block (forage selenium $<0.04 \mu \mathrm{g} / \mathrm{g} \mathrm{DM}$ ) and mated with a single
Suffolk ram following synchrony using CIDRs ${ }^{\mathrm{TM}}$. Animals were returned to the respective study plots in May 1998 and remained on the appropriate plots at all other times. Following pregnancy scanning in August 1998, five ewes bearing single foetuses and five ewes bearing twin foetuses were retained per treatment, remaining animals were sold.

Lambing commenced in late August 1998 and the lambs were identified immediately after birth. Initial concentrations of blood selenium collected from the NC lambs on 10 October 1998 were extremely low $($ mean $=89 \mathrm{nmol} / \mathrm{L})$. While no evidence of clinical selenium responsive disease was observed, for ethical and welfare reasons the $\mathrm{NC}$ animals were removed from the study. Data continued to be collected from lambs grazing the SRSe5 and PC plots during 1998/99.

Lambs were weaned at a target liveweight of $22 \mathrm{~kg}$, at which time the ewes were removed from the study.

\section{Animal measurements}

Liveweight: Ewes were weighed at the time of treatment allocation (November 1997), fortnightly for the first 4 months of the study and monthly thereafter. Weights were obtained following overnight fasting, however animals were weighed full immediately pre- and postlambing to avoid the possible induction of metabolic problems in pregnant and lactating ewes.

Lambs were weighed at the time of birth, then monthly from October 1998-May 1999. With the exception of lamb birthweight data, liveweight and blood selenium data were not collected between 24 August 1998 and 10 October 1998 due to concerns regarding mismothering and stress associated with yarding.

Blood sampling: Ten ewes were randomly chosen from each treatment for sampling for blood selenium concentration. Initial blood samples were collected in November 1997 , fortnightly ( \pm 2 days) from the same 30 animals for the first 16 weeks of the study and 4weekly ( \pm 1 week) thereafter. Blood samples were collected at the time of liveweight determination.

Blood samples were collected from all lambs for determination of blood selenium concentration beginning 10 October 1998. All lambs were sampled 4weekly ( \pm 1 week) until March 1999.

Pasture measurements: On nine occasions during the study 20 hand-plucked pasture samples were collected randomly across each plot. Samples were pooled and submitted for selenium analysis as described previously.

Statistical analysis: Blood and liveweight data were evaluated by analysis of variance using Genstat version 5.0. In this non-replicated experimental design, animal 
variation has been used for the estimation of variation and we acknowledge that treatment effects may be confounded by between paddock effects.

\section{Results}

Concentrations of blood selenium increased rapidly for the SRSe5 and PC ewes following the introduction of animals to plots in November 1997 (Figure 1). Mean selenium concentrations increased from less than 390 $\mathrm{nmol} / \mathrm{L}$ to peak concentrations of $4411 \mathrm{nmol} / \mathrm{L}$ and $3687 \mathrm{nmol} / \mathrm{L}$ for the SRSe 5 and PC animals respectively by week 17 of the study. Selenium concentrations declined steadily thereafter to reach concentrations of less than $1200 \mathrm{nmol} / \mathrm{L}$ by week 48 of the study. Concentrations of blood selenium were significantly lower $(\mathrm{P}<0.001)$ for $\mathrm{NC}$ animals compared with the SRSe5 and PC sheep (Figure 1). Further, concentrations of blood selenium for the SRSe 5 ewes were significantly greater $(\mathrm{P}<0.05)$ than those from $\mathrm{PC}$ animals on 11 of 16 sampling occasions.

Figure 1 Concentration of blood selenium for ewes (closed symbols) and lambs (open symbols) grazing SRSe5 (experimental selenium product, O), positive control (commercially available slow release selenium product,

口) or negative control (no selenium supplementation,

A). Bars show Least Significant Difference at $5 \%$ level.

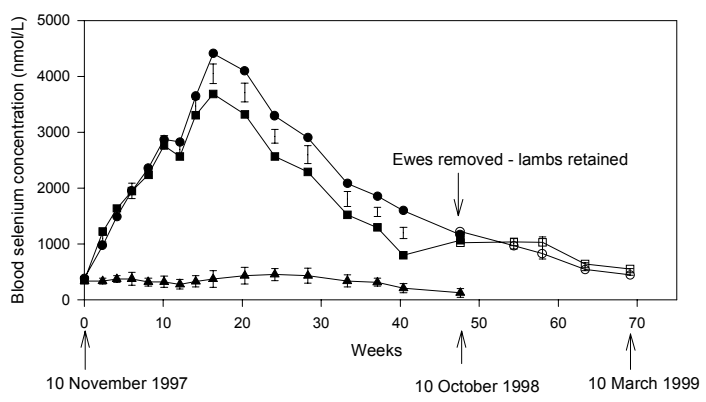

Blood selenium concentrations of the lambs from the SRSe 5 ewes were significantly greater $(\mathrm{P}=0.022)$ than those from the PC lambs (1222 vs $1025 \mathrm{nmol} / \mathrm{L}$, respectively) on 10 October 1998 . Blood selenium concentrations did not differ significantly between treatments on subsequent sampling occasions $(\mathrm{P}>0.1)$. Concentrations of lamb blood selenium were highly correlated with ewe blood selenium concentrations $\left(\mathrm{r}^{2}\right.$ $=+0.904 ; \mathrm{P}<0.0001$ ) (Figure 2) for samples collected on 10 October 1998, the only occasion on which blood samples were collected from both ewes and lambs.

Pasture selenium concentrations were assessed from each plot on nine occasions during the study (Figure 3).
Figure 2 Correlation between ewe and lamb blood selenium concentration on 10 October 1998.

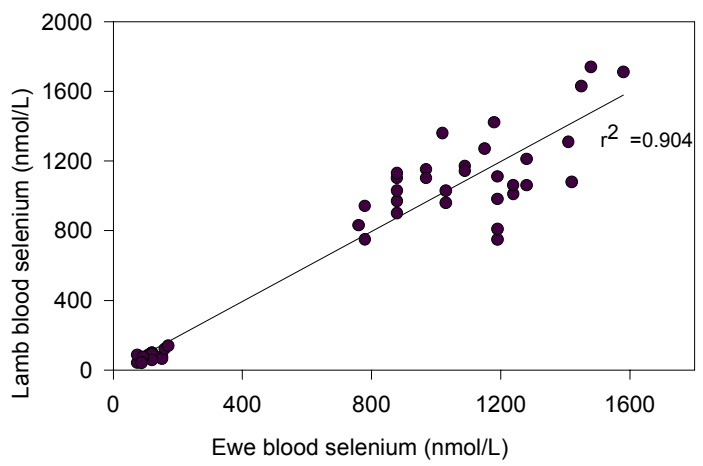

Figure $3 \log _{10}$ pasture selenium (ug/g DM) after application with a experimental selenium product (SRSe5, O), a commercially available slow release selenium product (positive control, $\boldsymbol{\Delta}$ ) and with no selenium product (negative control, $\mathbf{\square}$ ).

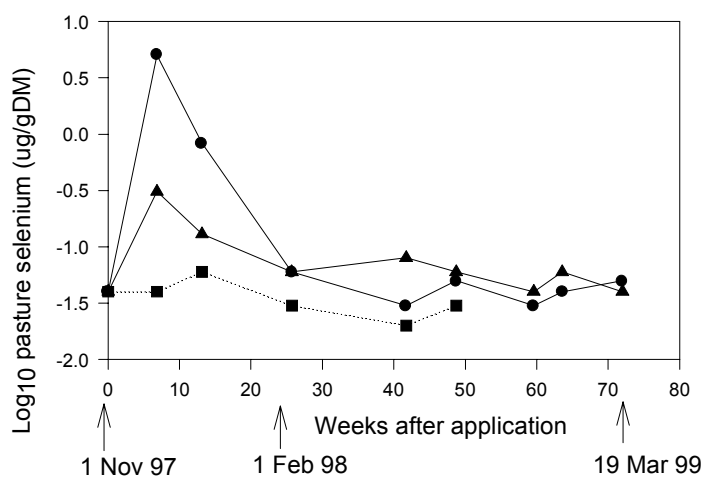

Pasture selenium concentrations peaked at 7 weeks after application for both SRSe5 and PC treatments (5.01 and $0.31 \mu \mathrm{g} / \mathrm{g}$ DM respectively).

Ewe liveweights did not differ significantly $(\mathrm{P}>0.1)$ between SRSe5, PC and NC groups (Table 1). Controlling for the effects of sex and birthrank, the mean SRSe 5 lamb birthweight was significantly greater when compared with the NC or PC lambs $(4.2,3.9$ and $3.7 \mathrm{~kg}$, respectively; $\mathrm{P}<0.05$ ) (Table 2 ). There were no significant differences in lamb liveweights at subsequent weighings (Table 2). We did not investigate possible associations between treatment and numbers of live lambs at birth because ewe selection was based on results of pregnancy scanning with equal numbers of single and multiple pregnancies allocated between treatments.

Blood selenium and liveweight outcomes for the $\mathrm{NC}$ treatment group are not reported for the second year because blood selenium concentrations (mean 89 $\mathrm{nmol} / \mathrm{L}$ ) collected in October 1998 were below those 
considered adequate for optimum health and productivity (Grace 1994). Metherell et al. (1996) reported lamb deaths associated with ewe blood selenium concentrations of less than $100 \mathrm{nmol} / \mathrm{L}$.

Table 1 Liveweights for ewes grazing SRSe5, positive control or negative control.

\begin{tabular}{|c|c|c|c|}
\hline \multirow[b]{2}{*}{ Treatment } & \multicolumn{3}{|c|}{------- Ewe liveweight $(\mathrm{kg})^{*}$} \\
\hline & $10 / 11 / 97$ & $4 / 3 / 98$ & $1 / 7 / 98$ \\
\hline SRSe5 & $54.4 \mathrm{a}$ & $54.8 \mathrm{a}$ & $62.2 \mathrm{a}$ \\
\hline Positive Control & $54.5 \mathrm{a}$ & $54.5 \mathrm{a}$ & $62.9 \mathrm{a}$ \\
\hline Negative Control & $56.0 \mathrm{a}$ & $55.1 \mathrm{a}$ & $62.6 \mathrm{a}$ \\
\hline Significance $(P<0.05)$ & NS & NS & NS \\
\hline \multicolumn{4}{|c|}{$\begin{array}{l}\text { * Values within a column with a letter subscript in common are } \\
\text { not significantly different based on Least Significant Tests } \\
\text { (t } 0.05 \text { ) }\end{array}$} \\
\hline
\end{tabular}

Table 2 Liveweights for lambs born to ewes grazing SRSe5, positive control or negative control.

\begin{tabular}{|c|c|c|c|c|}
\hline \multirow[b]{2}{*}{ Treatment } & \multicolumn{3}{|c|}{------ Lamb liveweight $(\mathrm{kg})^{\star}$} & \multirow[b]{2}{*}{$10 / 3 / 99$} \\
\hline & Birth & $15 / 10 / 98$ & $4 / 12 / 98$ & \\
\hline SRSe5 & $4.2 \mathrm{a}$ & $13.1 \mathrm{a}$ & $24.3 \mathrm{a}$ & $28.9 \mathrm{a}$ \\
\hline Positive control & $3.7 \mathrm{c}$ & $11.5 \mathrm{a}$ & $22.0 \mathrm{a}$ & $27.7 \mathrm{a}$ \\
\hline Negative control & $3.9 \mathrm{~b}$ & \# & \# & \# \\
\hline Significance $(P<0.05)$ & 0.036 & NS & NS & NS \\
\hline
\end{tabular}

* Values within a column with a letter subscript in common are not significantly different based on Least Significant Tests (t 0.05 )

\# Negative control lambs removed from study due to low concentrations of blood selenium

\section{Discussion}

This experiment confirmed the significant influence of selenium applications to pasture on the concentrations of blood selenium in grazing sheep reported previously (Hupkens Van der Elst \& Watkinson 1977; Grace 1994). Results from Year 1 demonstrated a significant, sustained elevation of blood selenium concentrations for ewes grazing pastures treated with the currently available commercial selenium product, $\mathrm{PC}$, and the new selenium product, SRSe5, compared with ewes grazing untreated pastures. While concentrations of blood selenium peaked then declined over a 12 month period, concentrations remained greater than $950 \mathrm{nmol} / \mathrm{L}$ for 11 months following the introduction of ewes to selenium treated pastures. During the same period, concentrations of blood selenium in the untreated sheep declined to less than $125 \mathrm{nmol} / \mathrm{L}$.

Lamb blood selenium concentrations were highly correlated with those of their respective ewes on the one occasion when blood was collected from both lambs and ewes. These results show that topdressing with selenium can prevent the onset of selenium deficiency in lambs from ewes grazing the treated pasture. Concentrations of blood selenium from lambs of the PC and SRSe 5 ewes remained greater than $450 \mathrm{nmol} / \mathrm{L}$ during the first few months of age. Blood selenium concentrations of greater than $250 \mathrm{nmol} / \mathrm{L}$ are considered indicative of selenium adequacy (Grace 1994).

Differences in concentrations of blood selenium between SRSe5 and PC groups were not accompanied by significantly different liveweights in ewes or lambs. In larger field studies, lamb liveweights at birth, midlactation and at weaning were significantly increased by selenium supplementation of ewes (Langlands et al. 1990), and a positive association between selenium supplementation and performance by merino wethers was reported by Western Australian workers (Whelan et al. 1994). Selenium supplementation was also associated with significantly increased liveweight gains and lamb survival rates in New Zealand merinos (Metherell et al. 1996). In the current study, blood selenium concentrations for the $\mathrm{NC}$ ewes remained greater than $125 \mathrm{nmol} / \mathrm{L}$ for most of the study period. In contrast, concentrations of blood selenium were $<$ $100 \mathrm{nmol} / \mathrm{L}$ where an association between selenium supplementation and animal performance was observed (Metherell et al. 1996). If the NC lambs with blood selenium concentrations $<100 \mathrm{nmol} / \mathrm{L}$ had remained in the current study for a longer period then a significant reduction in growth rates may have been seen. Failure to identify an association between blood selenium concentration and liveweight gains may also reflect the small numbers of sheep per treatment.

Associations between concentrations of pasture and blood selenium cannot be defined adequately from this study. Extremely high concentrations of selenium were detected in samples collected from the SRSe5 plot (5.01 $\mu \mathrm{g} / \mathrm{g}$ DM) in December 1998. This result is in the top $3 \%$ of all pasture selenium concentrations recorded by R.J. Hill Laboratories (Tony Kay pers. comm.) and may reflect contamination of pasture samples rather than true pasture selenium concentration. Previous work, which investigated pasture selenium concentrations associated with application of SRSe5 and PC at a Southland site, indicated similar peak concentrations for both products (Moorhouse \& Dumbleton, unpublished data). Preliminary results from other South Island sites suggest, however that SRSe5 may be associated with a relatively higher peak of pasture selenium concentration than PC-treated pastures (Moorhouse \& Dumbleton, unpublished data). Further work under replicated controlled experimental conditions is required to elucidate this relationship.

Topdressing pasture with selenium offers significant practical advantages to farmers relative to more direct 
methods of animal supplementation. Following oral dosing with $3 \mathrm{mg}$ selenium as $\mathrm{Na}_{2} \mathrm{SeO}_{4} \cdot 10 \mathrm{H}_{2} \mathrm{O}$, concentrations of blood selenium increased to greater than $350 \mathrm{nmol} / \mathrm{L}$ (Grace 1994), however concentrations remained elevated for less than 100 days. Further, efficacy of oral dosing may be questionable for young lambs under conditions of severe selenium deficiency (Metherell et al. 1996). Intra-ruminal selenium pellets are not always a practical supplementary option for lambs because pellets cannot be administered to animals under the age of 80 100 days (Whelan et al. 1994). Selenium status of lambs may be improved indirectly through supplementation of ewes because pre-mating treatment of ewes with longacting injectable selenium improved the selenium status of ewes as well as of the suckling lamb up to weaning (Metherell et al. 1996). Results from the current study also showed an association between the selenium status of ewes and their progeny, however pasture applied selenium products offer additional benefits of ease of application and reduced stock handling. Provided that approximately one-third of the farm is top-dressed with selenium amended fertiliser, this approach provides an efficacious and sustained means by which concentrations of blood selenium can be maintained in ewes and their suckling lambs.

\section{ACKNOWLEDGEMENTS}

The authors thank Chris Logan (Lincoln University) for the collection of blood samples and David Baird (AgResearch) for analysis of data described in this paper.

\section{REFERENCES}

Grace, N. 1994. Managing trace element deficiencies. pp. 9-24. Occasional publication, New Zealand Pastoral Agricultural Research Institute Ltd.

Hupkens Van Der Elst, F.C.C.; Watkinson, J.H. 1977. Effect of topdressing pasture with selenium prills on selenium concentration in blood of stock. New Zealand journal of experimental agriculture 5: 7985.

Langlands, J.P.; Donald, G.E.; Bowles, J.E.; Smith, A.J. 1990. Sub-clinical selenium insufficiency. 3. The selenium status and productivity of lambs born to ewes supplemented with selenium. Australian journal of experimental agriculture 31: 37-43.

Metherell, A.K.; Owens, J.L.; Moore, G.H.; Mackintosh, C.G. 1996. Selenium supplementation alternatives for the South Island high country. Proceedings of the New Zealand Grassland Association 58: 199204.

Whelan, B.R.; Barrow, N.J.; Peter, D.W. 1994. Selenium fertilisers for pastures grazed by sheep. II. Wool and liveweight responses to selenium. Australian journal of agricultural research. 45: 877-887.

Wichtel, J.J. 1994. Selenium in New Zealand dairy cattle: Recent developments. pp. 35-61. In: Mineral Nutrition. Veterinary continuing education, Massey University, Palmerston North, New Zealand, Publication No. 137. 
